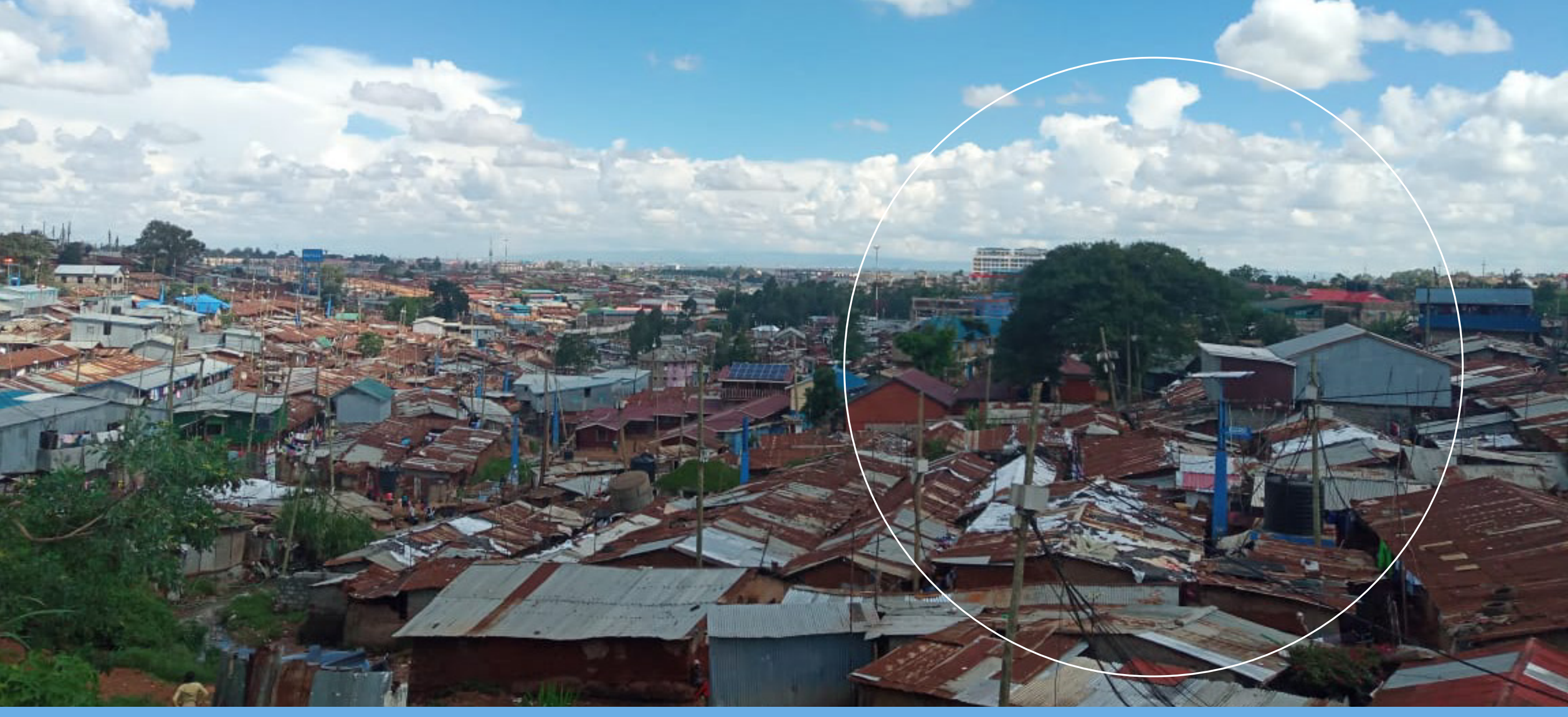

\title{
Social capital and food security in Kibera
}

Tinka Koster, Emma Termeer, Nina Motovska, Marvin Kunz, Oscar Ingasia Ayuya, Katrine Soma 
Tinka Koster, Emma Termeer, Nina Motovska, Marvin Kunz, Oscar Ingasia Ayuya, Katrine Soma, 2021. Social capital and food security in Kibera. Wageningen, Wageningen Economic Research, Report 2021-042. 21 pp.; 3 fig.; 2 tab.; 28 ref.

ISBN: 978-94-6395-807-3

This research was carried out within the motif 'Feeding cities and migration settlements', as part of the programme Food Security and Valuing Water (KB-35-002-001) of Wageningen University \& Research and was subsidized by the Dutch Ministry of Agriculture, Nature and Food Quality.

This report can be downloaded for free at https://doi.org/10.18174/546542 or at www.wur.eu/economic-research (under Wageningen Economic Research publications).

(C) 2021 Wageningen Economic Research

P.O. Box 29703, 2502 LS The Hague, The Netherlands, T +31 (0)70 33583 30, E communications.ssg@wur.nl,

http://www.wur.eu/economic-research. Wageningen Economic Research is part of Wageningen University \& Research.

\section{(cC) BY-NC}

This work is licensed under a Creative Commons Attribution-Non Commercial 4.0 International License.

(C) Wageningen Economic Research, part of Stichting Wageningen Research, 2021

The user may reproduce, distribute and share this work and make derivative works from it. Material by third parties which is used in the work and which are subject to intellectual property rights may not be used without prior permission from the relevant third party. The user must attribute the work by stating the name indicated by the author or licensor but may not do this in such a way as to create the impression that the author/licensor endorses the use of the work or the work of the user. The user may not use the work for commercial purposes.

Wageningen Economic Research accepts no liability for any damage resulting from the use of the results of this study or the application of the advice contained in it.

Wageningen Economic Research is ISO 9001:2015 certified.

Wageningen Economic Research Report 2021-042 | Project code 2282700540

Cover photo: Katrine Soma / Wageningen University \& Research

2 | Wageningen Economic Research Report 2021-042 


\section{Table of Contents}

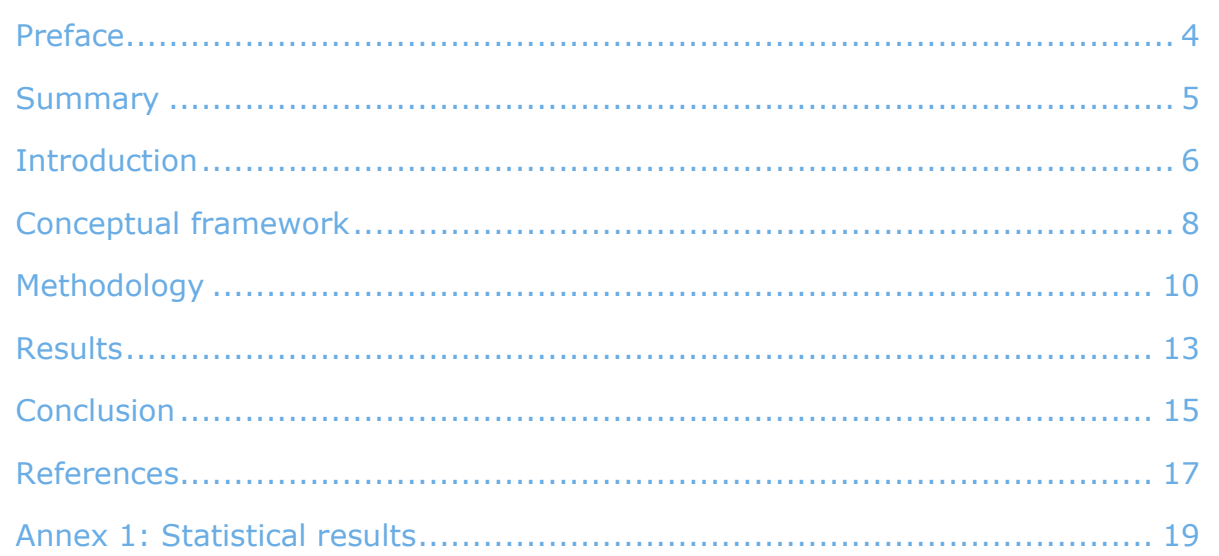


Sub-Saharan Africa is expecting high population growth in future, yet bearing the burden of high amounts of people living in poverty, and with food insecurity and nutrition shortages dominating millions of people's everyday life. People migrate into cities in search for work, safety and food security and a better life. This is also the case in Kibera, the largest slum in Nairobi. The complexities of the slums make it difficult to find solutions to these challenges.

In the research project 'Feeding cities and migration settlements' (2282700485540), which is part of the Wageningen University \& Research programme Food Security and Valuing Water (KB-35-002-001), and subsidised by the Dutch Ministry of Agriculture, Nature and Food Quality, we have reached out to Kibera to explore solutions and develop new insights. Applying a rural-urban food system approach, we have established a new fish value chain sourcing from a rural area called Nyeri County - not earlier linked with the slums of Nairobi - to deliver small-sized affordable fish not marketable elsewhere to Kibera. The new supply of fish is very much welcome as a nutritious contribution to people living in the Kibera slum. This new value chain has also provided an opportunity for further research. Accordingly, we have conducted a household survey with a unique dataset based on a total of 386 interviews, distributed equally across 13 villages in Kibera, to investigate a series of different relationships within the rural-urban food system. A series of surveys investigates food security related with fish consumption, with migration, with livelihood characteristics such as income, tribe, etc., as well as welfare factor relations with environmental issues such as water and energy and waste. A series of surveys will thus be finalised over the coming months. This survey is one of the first.
In this unique survey, the relationships between food security and social capital and trust, among others, have been analysed, and some invaluable findings are presented. I would very much like to thank the authors for the writing and analyses of this survey, and also a special thanks goes to Tinka Koster who also supported the preparations of the household survey with her expertise in designing high-quality household surveys, including the syntaxing.

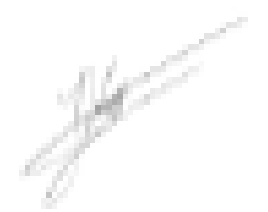

Prof.dr.ir. J.G.A.J. (Jack) van der Vorst General Director Social Sciences Group (SSG) Wageningen University \& Research 
The aim of this study is to explore the links between social capital and food security in Kibera, to contribute to a better understanding and targeting of food insecurity in vulnerable urban environments.

Understanding the drivers of food security is important to better address and design effective interventions in vulnerable environments. Social capital proves to be a valid determinant of differences in food security. The extent to which social capital can be an exploratory factor for food security in informal urban settings is unclear based on existing literature. Social capital is understood as the social resources between and within groups that people rely on when pursuing their livelihoods, including relations of trust and reciprocity, social networks and institutions. Three forms of social capital can be distinguished: bonding, bridging and linking. This paper uses data collected among 385 households in Kibera to explore the connection between different types of social capital and food security. To assess the relation between the proxies of the different types of social capital and food security, we use two linear regression models.
The results of this study indicate that different types of social capital can help to gain a more complete understanding of dynamics of household food security.

The results show that households that trust in their local community leaders are on average more food secure, while we do not observe a significant relation between trust in local politicians and food security. Cultural diversity is positively related to food security, indicating a potentially important relation between bonding social capital and food security. Households that visit their village of origin more often are on average more food secure, further confirming the positive relation between bonding capital and food security. Interestingly, trust in strangers was significant but negatively correlated with food security, indicating that the more people trust strangers, the less food secure their household. This finding requires further research, but potential explanations might be that this variable acts as an indicator for other variables that might explain negative correlation, such as living in highly populated areas or a lack of integration in the community. The results of our analysis suggest that social capital is a promising predictor of food security in Kibera and we advocate the future use of validated social capital measures to understand this process even better. 
Understanding the drivers of food security is important to better address and design effective interventions in vulnerable environments.

Food insecurity is one of the main prevalent issues faced by households in Sub Saharan African countries. Since 2014, undernourishment is on the rise with the largest share of undernourished people living in Eastern Africa (FAO 2020). Food insecurity is not only a health issue but has wider social, economic and policy implications, as lack of essential nutrients has a profound effect on economic productivity (Hamelin et al., 1999; Naicker and Teare 2015; Seligman and Schillinger 2017). Vulnerable and lower-income households specifically are more likely to suffer from increased food insecurity, and this more so in times of shocks and/or instability. Understanding what allows individuals and households to achieve and maintain food security is important to better address and design effective interventions in such environments.

Social capital proves to be a valid determinant of differences in food security. The extent to which social capital can be an exploratory factor for food security in informal urban settings is unclear based on existing literature.

Food insecurity is often associated with limited productivity in the agricultural sector and prevailing poverty affecting food availability (Sseguya 2018). New evidence however shows that 'despite increase in agricultural production in many parts of the world, the average per capita daily calorie and protein food availability is below the recommended values' (Sseguya et al. 2017). In Africa, the increasing food insecurity is predominantly attributed to conflict, unstable economies, and environmental degradation (FAO 2019). Gathering more evidence to understand how households can become more food secure in such situations has laid grounds for exploring the social dimensions and their effects on food security at household and/or communal level. Social capital refers to the social relations between and within groups of people that people rely on to live their lives, for example in the form of shared norms and values, networks and trust. Martin and colleagues (2004) found a positive relation between

\footnotetext{
${ }_{1}$ Also Gallagher et al. (2013), Misselhorn (2005), Mpanje, Gibbons and McDermottt (2018)
}

higher rates of social capital, defined as trust in one's neighbour, and a lower likelihood of experiencing hunger in studied households. Similarly, Chriest and Niles (2018) found a link between social and physical capital and this mainly in terms of access to information, food, and land. ${ }^{1}$ However, there is limited evidence on the forms of social capital and their relation to food security. This is especially prominent in the informal urban settings, where social capital takes on different forms given the high complexity of vulnerable environments (Mpanje, Gibbons and McDermott 2018).

The aim of this study is to explore the links between social capital and food security in Kibera, to contribute to a better understanding and targeting of food insecurity in vulnerable urban environments.

Urbanisation is expected to increase in low- and middle-income countries over the coming years, as people are in search of better opportunities for economic activity or driven by food insecurity. Compared to other regions, the rate of urbanisation in African countries is the highest globally, with the proportion of people living in slums rising. It has been forecasted that the size of the urban population will reach $52 \%$ by 2025 , being double the size compared to 1990 (APHRC 2012). This will likely lead to a rapid expansion and an overall increase in the number of slum areas. Slums are complex in terms of the link between social capital and food security. This is mainly due to migration flows and intricate, sometimes conflictual identity politics of urban dwellers - including ethnic affiliations (Cardosi et al. 2019: 105). In general, urban settlement residents are more vulnerable to food insecurity compared to formal situations, where crisis events affect food security of these populations to a significantly greater extent (Kimani-Murage et al. 2014). Kenya is one of the countries struggling with urban transitions, where slum populations are highly vulnerable to shocks and stressors to their food security (Beyer et al. 2016: 4). 
The Kibera slum in Nairobi provides a challenging and complex environment to test the interactions between social capital and food security.

The most recent official census in 2009 estimated the population of Kibera to be 170,070 , contrary to popular previous estimates of 1 million. A study in 2011 confirmed this newer estimation of about 170,000 residents (Desgroppes and Taupin 2011). The slum is divided in villages (see Figure 1) with varying populations, of which Makina is the largest. There is no formal land ownership in Kibera: the Kenyan government owns the land although it does not officially acknowledge the settlement. New residents largely come from rural areas in search for work, representing all the major Kenyan ethnic backgrounds (Mutisya and Yarime 2011). The rural to urban migration which characterises Kibera plays a key role in the social dynamics, as there can be conflicting identity politics and ethnic affiliations (Cardosi et al. 2019). Moreover, it is estimated that more than three quarters of the households in Kibera live below the poverty line (Gulyani and Talukdar 2010). Data on the food security situation in informal settlements in Nairobi show that most inhabitants have unstable incomes, of which $40-50 \%$ on average is spent on food, and lack important nutrients (Mohamed et al. 2016; Chege et al. 2010; Olack et al. 2014).

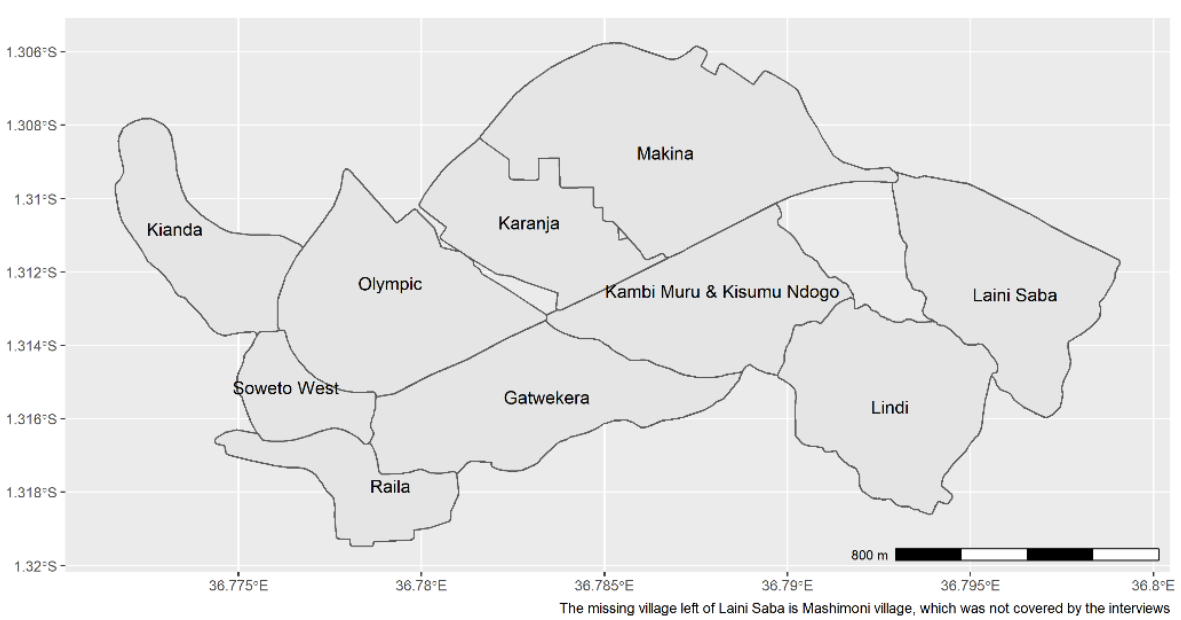

Figure 1 Map of the villages of Kibera

This paper uses data collected among 385 households in Kibera to explore the connection between different types of social capital and food security.

The following chapter provides the conceptual background to this study and discusses the concepts of food security, different types of social capital and vulnerable urban settings in more depth. The methodology chapter discusses the operationalisation of the food security and social capital variables. The results of the regression are displayed in the results section, after which conclusions and recommendations are drawn in the concluding chapter. 
Food insecurity is a multidimensional issue having long-term consequences on one's well-being including worsening academic, health and wider social performance.

FAO defines food security as a situation 'when all people, at all times, have physical and economic access to sufficient, safe and nutritious food' (2006, p. 1). This definition comprises four core elements of food security, namely food availability, access to food, utilisation of food and stable access to food. The level of food security can change dramatically in relatively short periods of time, which mainly happens in unstable situations or events of crisis -

economic, health, environmental crises or their combination (FAO 2006). Apart from negative health consequences, aggravated food insecurity can lead to a wider variety of outcomes influencing long-term well-being. Some of these are possible development issues, worsened school performance of children (Jyoti et al. 2005), development of psychological issues like depression and anxiety (Nanama and Frongillo 2012), and even increase in social tensions (Koren et al. 2021).

Social capital is understood as the social resources between and within groups that people rely on when pursuing their livelihoods, including relations of trust and reciprocity, social networks and institutions.

The concept of social capital first gained prominence in Robert Putnam's work, Bowling alone, on declining social capital in the United States (Putnam 2000). In it, Putnam focused on changing the perception on social capital to assigning it a value at the individual level. In other words, social capital aids individuals to work in a more effective and productive way to reach common objectives (Häuberer 2011). Social capital can be considered important as physical and human capital. When looking for access to services or goods, social capital can for instance be used to substitute lack of physical capital. While there are conceptual differences in defining social capital, there are broadly three types of social capital that have been commonly distinguished (Mpanje et al. 2018): First, bonding social capital refers to 'personal relations that are based on a sense of collective identity such as family, close friendship and the sharing of the same culture or ethnicity'. According to Martin et al. (2004), ethnicity plays an important role in achieving cohesion through sharing the same or similar cultural practices, values and norms. Identifying with a certain ethnic group also creates a sense of belonging and a higher sense of security and reliance on other members in times of hardship within the same group. The strength of such relations is further reflected in the central role of identity politics specifically related to political mobilisation in Kenya and several other African countries. Hence, cultural diversity is a strong indicator of collective identity and bonding social capital. This type of social capital is commonly associated with trust and reciprocity. Second, bridging social capital refers to 'people's relations or links that stretch beyond a shared sense of identity, for example to distant friends, colleagues and associates'. Third, linking social capital can be defined as relations between people or groups and societal institutions, reflecting power, wealth and societal status. Although there is general consensus of the key indicators of social capital, such as levels of trust, participation, networks etc., the concept has been criticised for its complexity and 'vagueness' (Roche 2004).

In recent years, the extent to which people rely on their social relations and networks has increasingly been discussed as an important determinant in contexts of food insecurity.

Several studies have pointed to the important role social capital plays in situations of food insecurity. One of the first studies to make the link between social capital and food security explicit is Martin et al. (2004), in which social capital at both community and household level was significantly associated with household food security among low-income households in the US.

Particularly reciprocity among neighbours appeared to be a large contributor The link has also been studied in African contexts, mostly to determine the effect on food security in rural areas. Danzja et al. (2013) find social capital has a positive influence on food security, although the effects vary depending on the form of social capital. Sseguya et al. (2018) find similar results, as households with bridging and linking social capital tended to be more food 
secure, as well as households with social capital in the form of cognitive bonding (i.e. awareness of generalised norms and mutual trust). In the context of Kibera, Gallaher et al. (2013) studied the link between urban agriculture, social capital and household food security. They found that participation in urban agriculture increases social capital - measured by exchange of goods and services between households and quality of relationships with urban neighbours -, which in turn has a positive impact on household food security.

The relation between social capital and food security can be explained through increased levels of household resilience.

Explanations for why social capital has a positive influence on household food security vary from effects on a more individual level - such as the ability to interact and exchange goods with community members - to the community level, where trusted networks and reciprocity play an important role. Often mentioned in this regard is that social capital increases the resilience capacity of households, thereby contributing positively to food security. Resilience can be defined as the ability of households to withstand and adapt to shocks, such as chronic low food availability (Beyer et al. 2016). In contexts with generally lower levels of other sources of capital, reliance on social networks plays a more prominent role in achieving the adaptive capacity to withstand food insecure situations (Bernier and Meinzen-Dick 2014). Understanding the interaction between different forms of social capital and their effect on household food security is key in vulnerable urban environments such as informal settlements, where other forms of physical capital are generally lacking.
An important aspect to consider is that social capital may differ in vulnerable urban settings, such as in the context of Kibera.

There are broadly two main types of social capital definitions - ones focusing on social capital facilitating social action to reach wider collective objectives; others emphasising the value of social networks as means to access services or goods in general. Social capital tends to play a more significant role in situations with lack of physical capital, where social capital can be considered a viable substitute. For the most part, social capital is measured in intensities of defined social networks or social relations. Depending on the type, social capital can be measured based on the number of memberships in community organisation, strength of relations within one' s neighbourhood, and others. What is clear is that these concepts point to the versatility of the concept in terms of the variety of forms that allow for measuring of social capital. Hence, the challenge to reach a universal description allows for substantial flexibility in defining a theoretical framework. While this is considered a conceptual weakness of social capital by many, diverse settings require one to understand 'what constitutes such capitals and how they can be measured ... based on context-specific issues and indicators [that] can be better adapt to diverse contexts' (Mpanje et al. 2018, p. 11). High levels of informality, not clearly defined land ownership rights, high population density as well as the aspect of rural-urban migration in Kibera were thus all taken into consideration when deciding on choice indicators for the bridging, bonding and linking social capitals in this study. A more detailed description on the indicator selection can be found in the methodology section. 
In this section, we describe the indicators used to measure different forms of social capital, and why we made the decision for these variables. Besides, we give a short overview of the distribution of the data on these indicators in the sample.

To explore the link between social capital and food security, we use household survey data collected in Kibera through random selection of respondents.

The data was collected using a randomly selected sample of 285 households in twelve villages in Kibera. A two-stage cluster sample design was adopted for the survey involving a selection of clusters, households and eligible individuals. In the first stage, Kibera was clustered into fourteen villages. Two villages were dropped because of insecurity reasons and the remaining twelve villages were allocated an equal sample. The last stage of sampling involved the use of Personal Digital Assistants (PDAs) at the time of survey, where respondents were randomly selected from the complete eligible target population. The selection of the respondent was by use of random walk. The field supervisor selected the starting point by identifying important land marks in the cluster e.g. school, churches/mosque, health facility, market etc. The minimum land mark in a village was 10 and the script selected the starting point randomly. After getting the starting point, the script selected the direction from the starting point and the sampling interval in selecting the respondent. In total, 385 respondents responded to the survey. The sample was dominated by female respondents (number of female respondents $=292$, number of male respondents $=93$ ). The age of the respondents ranged from 19 to 59 , with a mean age of 32 years and a median of 30 years.

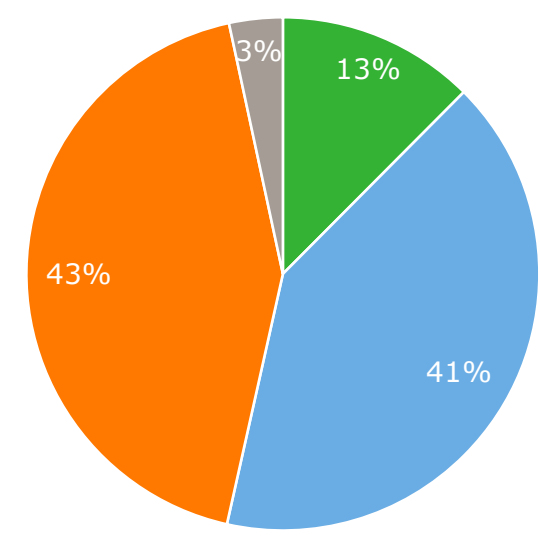

- Food secure $\square$ Mildly secure $\|$ Moderately insecure $"$ Severely insecure

Figure 2 Categories of food security, $n=385$

\section{Variables of interest}

Food security

We use the Household Food Insecurity Access Scale (HFIAS) developed by FAO as a proxy for food security (Coates et al. 2007). This scale is an accumulated measure based on several food consumption related questions, for example 'In the past four weeks, did you worry that your household would not have enough food?'. In our dataset, the responses ranged from 0 to 22, while the scale ranged from 0 to 27 . While the scale normally measures food insecurity, we transformed it so that a high score indicates food security, as that provides a more intuitive scale for this study. More specifically, we did a linear transformation in which we first subtracted the maximum value (22) from each observation and then multiplied it by -1 , in order to inverse all of the values. Hence, the higher the score, the more food secure (and the less food insecure) the household. The scale can be categorised into four groups, as shown in Figure 2. 
Social capital

As social capital was not directly measured in the survey, we used variables that were collected and that broadly represented social capital or one of the previously discussed subcategories. These are cultural diversity, visits to area of origin, trust in strangers, trust in local politicians and community leaders to measure bonding, bridging and linking social capital.

Bridging and linking social capital were measured through questions looking at trust into the local politicians, trust in the community leaders, and trust in strangers.

Trust lays the basis for forming a relation between two entities and to a certain extent defines the type of relation. Trust, therefore, creates social capital and is one of the most used variables of social capital in existing studies. Our study looked at trust in relation to different groups to observe on the one hand bridging social capital and on the other linking social capital. Trusting strangers was used to assess whether expanding social ties to groups outside of the shared identity one, as a form of bridging social capital, could explain household food security. For linking social capital, we investigated trust in community leaders and the trust in local politicians as that allowed to gain an understanding of the relations between people or groups and societal institutions. Levels of trust ranged from very low to very high. Figure 3 displays the levels per individual group. A very high trust level was the least indicated across all groups, whether local politicians or strangers. Besides, we used the membership of social organisations as another proxy for linking socia capital. Fifty-eight per cent of the households in our sample have a household member that is member of any kind of social group.

Bonding social capital was assessed through the number of visits to rural origins and cultural diversity.

Characterised by high rural-urban migration, new dwellers oftentimes strongly rely on assistance from families from their areas of origin, especially in situations of high insecurity (Shimamura et al. 2017). Number of visits was therefore a good proxy for better understanding the maintaining of such ties and their intensity. Visits to the village of origin was measured by the question, 'How often do you visit your rural areas in a year?'. The average respondent visited their village of origin and its rural area 2.51 times a year, and the number of visits ranged from 1 to 9 after some outliers were removed. The number of visits to the rural areas probably depends on the distance to these areas of origin. However, the actual amount of visits is a more accurate proxy of social capital, as social bonds arguably depend more on the intensity of the contact than the physical distance. Cultural diversity allowed us to further explore bonding social capital as this variable provides a good indication of collective identity. We measured it with the question 'What percentage of your neighbours share your same cultural practices?'. The percentage of neighbours sharing cultural practices was $45 \%$ on average and ranged from 0 to 100 .

To provide accurate representation of the data, outliers were removed from the dataset.

When investigating the data in more detail, we removed three households due to partly inconsistent or potentially faulty responses. One of these cases had a seemingly incorrectly reported food security score and was therefore excluded from the sample. A second one had, while theoretically possible, unreasonably high indications for visits to the home village, while no other data points would support such an extreme measure. The third had several extreme response patterns and was therefore also estimated to be a potential outlier. All three data points skewed the data considerably and we could not determine whether these responses were artefacts or accurate data points.

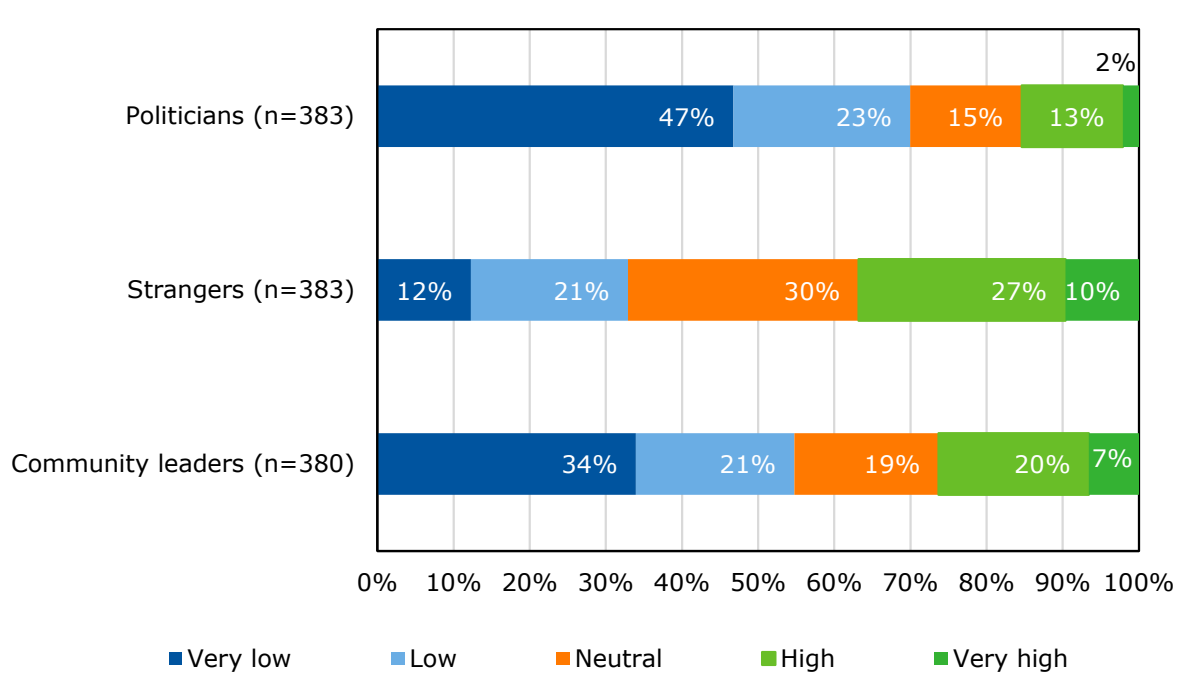

Figure 3 Levels of trust in different groups 
We have selected a few variables to include in our analysis in order to control for their potentially confounding effects on the relation between social capital and food security. These variables are age, gender, and education of the household head, as well as the years that the household has spent in Kibera and household size. We expect that these descriptive social demographic variables can influence the effect of social capital on food security, therefore, we control for them in our regression analysis.

To assess the relation between the proxies of the different types of social capital and food security, we use a linear regression model.

A regression analysis allows us to better understand how well the variables we selected were able to explain the variance in the results of the food security score. The linear regression model we implemented used food security as the dependent variable while it used all of the above variables as independent variables. The independent variables were checked for normality, standardised and the previously discussed outliers were removed when they skewed the data beyond a reasonable extent and had to be considered as unreliable data entries. We used two main models to estimate the relation between food security and different forms of social capital. In the first model, we looked at the separate relation between each of the social capital indicators and food security and then ran another final model in which we regressed all variables combined on food security. As correlations between the predictors were not significant, one can consider the final model as an accurate multiple regression. In the final regression model, food security was predicted by (all regression coefficients are standardised):

Food security score $=\beta_{0}+\beta_{1} *$ CoEthnicity $+\beta_{2} *$ Trust strangers $+\beta_{3} *$ Origin visits $+\beta_{4}$ $*$ Trust community leaders $+\beta_{5} *$ Membership of social organisations $+\beta_{6} *$ Trust local politicians $+\beta_{7} *$ Household size $+\beta_{8}$

$*$ Household head age $+\beta_{9} *$ Household head education $+\beta_{10}$ $*$ Household head gender $+\beta_{11} *$ Years in Kibera
As stated before, we report the regression results for our multiple linear regression with and without outliers. Furthermore, we controlled for a range of variables that need to be kept stable across participants in order to exclude the effect of demographic factors on the regression. As we did not conduct the survey in an experimental setting with a relatively limited sample, we cannot draw any conclusions about causality. The results presented in the next section can therefore be seen as an association which can be further explored in future research and interventions. 


\section{Results}

We can explain up to $14.5 \%$ of variance in food security with the selected independent and control variables.

Of the five variables that we considered as independent variables, four were significant. Cultural diversity, trust in the community leaders, and visits to the village of origin were significant and indicated a linear relationship with food security in the hypothesised direction (i.e., they were positively related). The estimated effect of the here discussed variables on food security is only smal (Cohen 1992).

Households that trust in their local community leaders are on average more food secure, while we do not observe a significant relation between trust in local politicians and food security.

Trust in local politicians and local community leaders were both used as proxies for linking social capital in this study. Trust in local community leaders was positively related to food security. This is in line with the expected relation resulting from the theory on linking social capital. However, trust in politicians did not show a significant relation to food security. We then performed an additional analysis to see whether indicators such as membership in various organisations, associations or community groups could help provide more understanding in the dynamics between food security and linking social capital. However, we found no relation between membership of these kind of groups and food security.
Table $1 \quad$ Summary table of regression analysis results

Indicator

Regression model

\begin{tabular}{ll} 
& Cultural diversity \\
\cline { 2 - 2 } Bonding social capital & Number of visits to the area of origin \\
\hline Bridging social capital & Trust in strangers \\
\hline Trust in local politicians \\
\hline Trust in community leaders \\
\cline { 2 - 2 } & Membership of social organisations \\
\hline
\end{tabular}

$\begin{array}{ll}\text { NS } & \text { Statistically significant positive } \\ \text { Statistically non-significant } \\ \text { Statistically significant negative }\end{array}$

Cultural diversity is positively related to food security, indicating a potentially important relation between bonding social capital and food security.

Cultural diversity and number of visits to area of origin were used to resemble bonding social capital in our study. Our results showed a significant and positive relation between cultural diversity and food security, which is in line with our expectations. This means that households with a higher share of their neighbours sharing their cultural practices are on average more food secure. 
Households that visit their village of origin more often are on average more food secure, further confirming the positive relation between bonding capital and food security.

We use the number of visits paid to the village of origin as second proxy for bonding social capital in the context of Kibera. The outcomes of our statistical analysis show that households that visit their origins more often are more food secure on average. This is in line with the theory that households with high bonding social capital are able to rely on their close network and receive help to access food and prevent hunger or malnutrition during crises. This is also in line with the previous finding, where people who share their cultural practices with a larger share of their neighbours also are more food secure. We also have data from Kibera indicating whether households bring food from their rural origins. We performed a quick analysis relating whether a household brings or gets gifted food from their rural origins to food security, but did not find any relation. Therefore, the relation between visiting rural origins more often and increased food security does not seem to work through actually receiving or bringing food. A reason for this might be because the distance might be too big to actually transport a lot of food.
Interestingly, trust in strangers was significant but negatively correlated with food security, indicating that the more people trust strangers, the less food secure their household

This likely means that the uncertainty in such relations is very high, in stark contrast to our findings for bonding social capital. In our case, trusting strangers points to a higher risk relation, which can result in increased food insecurity. For instance, borrowing money through informal transactions as the last resort to purchase food, may result in inability to repay if interest rates are set too high rendering one more food insecure. Our results can be substantiated by a weak regulatory framework, high prevalence of poverty, proneness to conflict generating a rather low-level trust environment in Kibera. A study looking at the relation between religious group membership and development in Kibera reached similar findings with saving group members being unable to trust and pool savings due to the above-mentioned reasons (Deacon 2014). Trust can indeed increase one's vulnerability depending on the studied situation indicating the level of risk (Nooteboom 2006), and contextual characteristics are an essential source to explain differing findings across cases. As such, there is another possible explanation specific to Kibera. In presence of lack of other types of social capital, such as bonding and/or linking capital, bridging capital is the most likely alternative. In this case, trusting a stranger, even being a riskier relation, might be a question of necessity rather than choice in absence of closer personal ties. 
Understanding the drivers of food security is important to better address and design effective interventions in vulnerable environments.

Social capital proves to be a valid determinant of differences in food security. The extent to which social capital can be an exploratory factor for food security in informal urban settings is unclear based on existing literature. The aim of this study is to explore the links between social capital and food security in Kibera, to contribute to a better understanding and targeting of food insecurity in vulnerable urban environments. The Kibera slum in Nairobi provides a challenging and complex environment to test the interactions between social capital and food security. We use data collected among 385 households in Kibera to explore the connection between different types of social capital and food security.

Food security is a multidimensional issue having long-term consequences on one's well-being including worsening academic, health and wider social performance.

Social capital is understood as the social resources between and within groups that people rely on when pursuing their livelihoods, including relations of trust and reciprocity, social networks and institutions. In recent years, the extent to which people rely on their social relations and networks has increasingly been discussed as an important determinant in contexts of food insecurity. The relation between social capital and food security can be explained through increased levels of household resilience. An important aspect to consider is that social capital may differ in vulnerable urban settings, such as in the context of Kibera.
The data was collected using a randomly selected sample of 385 households in twelve villages in Kibera.

Our main analysis consists of variables that we assessed to be connected to different forms of social capital in Kibera. Questions looking at trust into the local politicians, trust in the community leaders, and trust in strangers were used to measure both bridging as well as linking social capital. We looked at number of visits to rural origins and cultural diversity to understand how bonding social capital relates to household food security in Kibera. To assess the relation between the proxies of the different types of social capital and food security, we use a linear regression model. We have selected a few variables to include in our analysis in order to control for their potentially confounding effects on the relation between social capital and food security.

We can explain up to $14.5 \%$ of variance in food security with the selected independent and control variables.

Households that trust in their local community leaders are on average more food secure, while we do not observe a significant relation between trust in local politicians and food security. Cultural diversity is positively related to food security, indicating a potentially important relation between bonding social capital and food security. Households that visit their village of origin more often are on average more food secure, further confirming the positive relation between bonding capital and food security. Interestingly, trust in strangers was significant but negatively correlated with food security, indicating that the more people trust strangers, the less food secure their household is. These results provide interesting insights into the potential relation between food security and social capital, but the study is explorative and the questions were not specifically designed to measure social capital. Hence, it would be an interesting next step to further investigate different proxies for social capital and their relation to food security. 
Different types of social capital can help to gain a more complete

understanding of dynamics of household food security.

A better understanding of the process of how social capital affects food security will aid policy makers and decision-makers to address food security with appropriate measures. Our analysis suggests that there are important relations between different types of social capital and food security. Social interactions and an embedding in a functioning set of social relationships seem to help too, as the increased food safety due to more visits to the place of origin suggest. In general, many of the variables that suggest closer social ties with people seem to help with food security. Further exploring these dynamics and mechanisms could help understand drivers of food insecurity, as well as potentially provide solutions.

The future role of social capital for food security in Kibera is an important one. While Kibera is already benefitting from programmes aimed at community strengthening and engagement, we suggest that these social programs need to be better understood in the context of their contribution to food security. If a food security context is taken into account from the start, such programs might increase the impact of social capital on food security. Future research should use dedicated social capital items and scales which would allow to more accurately assess the impact of social capital on food security.

Furthermore, while $14.5 \%$ of explained variance in food security does not seem much, these $14.5 \%$ might add a lot on top of more classical variables, such as physical capital.
Performance of loosely amassed social capital variables already show promising results, supporting the need for dedicated social capital measures. The proxies we analysed already show some promising results. Using dedicated social capital questionnaires will likely result in more reliable and promising results. Then, we expect that the effect of social capital can be determined with much more confidence. and help policy and decision-makers to recognise the important role that social capital plays by itself and as a part of interventions (van Rijn, Nkonya and Adekunle 2015) to guarantee food security for urban African communities. 
African Population and Health Research Center (2012). Population and Health Dynamics in Nairobi's Informal Settlements. Nairobi, Kenya: African Population and Health Research Center.

https://assets. publishing.service.gov.uk/media/57a089f240f0b649740003 38/NCSS2-FINAL-Report.pdf.

Bernier, Quinn and Meinzen-Dick, Ruth Suseela. (2014). Resilience and social capital. 2020 Conference Paper 4. May 17-19, Addis Ababa, Ethiopia. Washington, D.C.: International Food Policy Research Institute (IFPRI). http://ebrary.ifpri.org/cdm/ref/collection/p15738coll2/id/128152

Beyer, L. I., Chaudhuri, J., and Kagima, B. (2016). Kenya's focus on urban vulnerability and resilience in the midst of urban transitions in Nairobi. Development Southern Africa, 33(1), 3-22.

Cardosi, G., Lizarralde, G., Kibue, S. N., and Bornstein, L. (2019). Multilevel Informality: Migration, Spatial Organization and Control in the Toi Market in Kibera (Nairobi). In Resettlement Challenges for Displaced Populations and Refugees (pp. 105-120). Springer, Cham.

Chege, P., Kuria, E., and Kimiye, J. (2010). A comparative study on dietary practices, morbidity patterns and nutrition status of HIV/AIDS infected and non-infected pre-school children in Kibera slum, Kenya. Journal of applied Biosciences, 32.

Coates, J., Swindale, A., and Bilinsky, P. Household Food Insecurity Access Scale (HFIAS) for Measurement of Household Food Access: Indicator Guide (v. 3). Washington, D.C.: Food and Nutrition Technical Assistance Project, Academy for Educational Development, August 2007.
Deacon, G. (2014). Pentecostalism and development in Kibera informal settlement, Nairobi. In Rakodi, C. (eds.) Religion, Religious Organisations and Development: Scrutinising religious perceptions and organisations (pp. 43-54). London \& New York: Routledge.

Dzanja, J. L., Christie, M., Fazey, I., and Hyde, A. G. (2013). The role of socia capital on rural food security: the case study of Dowa and Lilongwe Districts in Central Malawi. Access International Journal of Agricultural Sciences, 1(4), 46-56.

Desgroppes, A., and Taupin, S. (2011). Kibera: The biggest slum in Africa?. Les Cahiers d'Afrique de I'Est/The East African Review, (44), 23-33.

de Smedt, J. (2011). The Nubis of Kibera: a social history of the Nubians and Kibera slums. Unpublished PhD thesis, Leiden.

Gallaher, C. M., Kerr, J. M., Njenga, M., Karanja, N. K., and WinklerPrins, A. M. (2013). Urban agriculture, social capital, and food security in the Kibera slums of Nairobi, Kenya. Agriculture and human values, 30(3), 389-404.

Gulyani, S., and Talukdar, D. (2010). Inside informality: The links between poverty, microenterprises, and living conditions in Nairobi's slums. World Development, 38(12), 1710-1726.

Habitat, U.N. (2020). State of the World's Cities. Nairobi, Kenya: UN Habitat.

Hair, J.F., Black, W. C., Babin, B.J., and Anderson, R.E. (2010). Multivariate data analysis (7th ed.). Englewood Cliffs: Prentice Hal

Cohen, J. (1992). A power primer. Psychological bulletin, 112(1), 155. 
Kimani-Muraha, E.W., Schofield, L. Wekesah, F., Mohamed, S., Mberu, B., Ettarh, R., Egondi., T., Kyobutungi, C., and Ezeh. A. (2014). Vulnerability to Food Insecurity in Urban Slums: Experiences from Nairobi, Kenya. Journal of Urban Health, 91(6): 1098-1113.

Martin, K.S., Rogers, B.L., Cook, J.T., and Joseph, H. M. (2004). Social capital is associated with decreased risk of hunger. Social science \& medicine, 58(12), 2645-2654.

Mohamed, S.F., Mberu, B.U., Amendah, D.D., Kiman Murage, E.W., Ettarh, R., Schfield, L., Egondi, T., Wekesah, F., and Kyobutungi C. (2016). Poverty and uneven food security in Urban slums. Crush J. and Battersby (eds.) Rapid Urbanisation, Urban Food Deserts and Food Security in Africa (2016), DOI 10.1007/978-3-319-43567-1_8

Mpanje, D., Gibbons, P., and McDermott, R. (2018). Social capital in vulnerable urban settings: an analytical framework. Journal of International Humanitarian Action, 3(1), 4.

Mutisya, E., and Yarime, M. (2011). Understanding the grassroots dynamics of slums in Nairobi: the dilemma of Kibera informal settlements. Int Trans J Eng Manag Appl Sci Technol, 2(2), 197-213.

Nooteboom, B. (2006). Social Capital, Institutions and Trust. (CentER Discussion Paper; Vol. 2006-35). Organization.

Olack, B., Feikin, D.R., Cosmas, L.O., Odero, K.O, Okoth, G.O., Montgomery, J.M, and Breiman, R.F. (2014). Mortality Trends observed in population-based surveillance of an urban slum settlement, Kibera, Kenya, 2007-2010. PLOS ONE 2014, 9(1).
Prayitno, G., Matsushima, K., Jeong, H., and Kobayashi, K. (2014). Social capital and migration in rural area development. Procedia Environmental Sciences, 20, 543-552.

Roche, M. (2004). Social policy and social capital: a clear case of putting merit before method?. Social Policy and Society, 3(2), 97.

Shimamura, Y., Yang, J., Baffoe, G., Dodoo, J., Mwakesi, I., Matsuda, H., Kiemo, K., Mutune, J., Mutisya, E., Mungai, D., Chen, C., Nagao, M., Mino, T., and Ikeda, I. (2017). Rethinking the Kibera 'Slum': The Role of Social Networks as a Mechanism for Coping with the Increased Demand for Job Opportunities. Journal of economics and sustainable development, 8, 157-169.

Sørensen, J.F. (2016). Rural-urban differences in bonding and bridging social capital. Regional Studies, 50(3), 391-410.

Sseguya, H., Mazur, R.E., and Flora, C.B. (2018). Social capital dimensions in household food security interventions: implications for rural Uganda. Agriculture and Human values, 35(1), 117-129.

van Rijn, Fédes, Ephraim Nkonya, and Adewale Adekunle. 'The impact of agricultural extension services on social capital: an application to the SubSaharan African Challenge Program in Lake Kivu region'. Agriculture and Human Values 32.4 (2015): 597-615. 


\section{Annex 1: Statistical results}

We analysed several models to understand the effect of the predictors on food security. Finally, we regressed all of the dependent variables on food security in one cumulative model with all predictive variables. The results of these estimations are reported below in Table 2 . The multiple linear regression was able to explain roughly $14,5 \%$ of the variance in food insecurity (Adjusted $\mathrm{R}^{2}$ of 0.145 ). A result of this size is statistically significant and suggests that our results are not caused by chance but by an actual relationship between the predictors of social capital and food insecurity. Whether this relationship is causal or correlational cannot be said as the source of the data does not allow for this kind of conclusion. While interpreting the results below, please note that the dependent variable is food security. Hence, a positive coefficient indicates that a higher score on the independent variable is related with more food security, or less food insecure households.

Model 7 (the model containing all social capital indicators) confirms the results of Models 1-6 (models with separate social capital indicators) except for the cultural diversity indicator (Model 1 ). This effect is probably absorbed by any of the other indicators. We checked whether this is caused by a potentially problematic level of collinearity, and it is not as all VIF scores are below 2 . According to Hair et al. (2010) only VIF scores of over 4 is problematic. Also the linear relations between co-ethnic and the other predictors is not high overall. While there is a significant correlation between cultural diversity and trust in the community the correlation is only -0.1 , hardly collinear. 
Table 2 Regression results

\begin{tabular}{|c|c|c|c|c|c|c|c|}
\hline & Model 1 & Model 2 & Model 3 & Model 4 & Model 5 & Model 6 & Model 7 \\
\hline \multirow[t]{2}{*}{ Cultural diversity } & 0.6649 & & & & & & 0.7058 \\
\hline & $(0.32)^{*}$ & & & & & & $(0.32)$ \\
\hline \multirow[t]{2}{*}{ Trust strangers } & & -0.7403 & & & & & -0.9927 \\
\hline & & $(0.35)^{*}$ & & & & & $(0.35)^{* *}$ \\
\hline \multirow[t]{2}{*}{ Origin visits } & & & 0.9417 & & & & 1.0169 \\
\hline & & & $(0.43)^{*}$ & & & & $(0.43)^{*}$ \\
\hline \multirow[t]{2}{*}{ Trust community leaders } & & & & 0.8578 & & & 0.9055 \\
\hline & & & & $(0.35)^{*}$ & & & $(0.36)^{*}$ \\
\hline \multirow[t]{2}{*}{ Trust local politicians } & & & & & 0.2369 & & 0.2715 \\
\hline & & & & & $(0.33)$ & & $(0.34)$ \\
\hline Membership of social & & & & & & -0.2527 & -0.2613 \\
\hline organisations & & & & & & $(0.35)$ & $(0.33)$ \\
\hline \multirow[t]{2}{*}{ Household size } & -1.0702 & -1.0774 & -1.0711 & -1.1195 & -1.0929 & -1.0699 & -1.0314 \\
\hline & $(0.4)^{* *}$ & $(0.4)^{* *}$ & $(0.4)^{* *}$ & $(0.39)^{* *}$ & $(0.40)^{* *}$ & $(0.41)^{* *}$ & $(0.39)^{* *}$ \\
\hline \multirow[t]{2}{*}{ Age household head } & -0.4183 & -0.2759 & -0.4366 & -0.1416 & -0.3375 & -0.3106 & -0.1373 \\
\hline & $(0.51)$ & $(0.51)$ & $(0.51)$ & $(0.52)$ & $(0.52)$ & $(0.52)$ & $(0.51)$ \\
\hline Education level & 0.5526 & 0.6607 & 0.7118 & $0.9643 *$ & 0.7615 & 0.7788 & 0.6181 \\
\hline household head & $(0.47)$ & $(0.46)$ & $(0.46)$ & $(0.46)$ & $(0.46)$ & $(0.47)$ & $(0.46)$ \\
\hline \multirow[t]{2}{*}{ Female household head } & 0.2517 & 0.1821 & 0.2756 & 0.2543 & 0.2033 & 0.1632 & 0.3489 \\
\hline & $(0.36)$ & $(0.36)$ & $(0.36)$ & $(0.36)$ & $(0.36)$ & $(0.37)$ & $(0.35)$ \\
\hline \multirow[t]{2}{*}{ Years in Kibera } & 0.4860 & 0.4374 & 0.6016 & 0.4838 & 0.4596 & 0.4840 & 0.5811 \\
\hline & $(0.45)$ & $(0.45)$ & $(0.46)$ & $(0.45)$ & $(0.46)$ & $(0.46)$ & $(0.44)$ \\
\hline \multirow[t]{2}{*}{ Intercept } & 14.4750 & 14.5434 & $14.5701(0.35)^{* * *}$ & 14.5612 & $14.4793(0.36)^{* * *}$ & 14.5177 & 14.6568 \\
\hline & $(0.35)^{* * *}$ & $(0.35)^{* * *}$ & & $0.35)^{* * *}$ & & $(0.36)^{* * *}$ & $(0.35)^{* * *}$ \\
\hline $\mathrm{R}^{2}$ & 0.071 & 0.072 & 0.073 & 0.079 & 0.052 & 0.052 & 0.144 \\
\hline$F$ for change in $R^{2}$ & $3.328^{*}$ & $3.375^{*}$ & $3.422 *$ & $3.623 *$ & $2.67 *$ & $2.67 *$ & $3.779 * * *$ \\
\hline
\end{tabular}




\section{Wageningen Economic Research}

P.O. Box 29703

2502 LS The Hague

The Netherlands

T +31 (0)70 3358330

E communications.ssg@wur.n

www.wur.eu/economic-research

Wageningen Economic Research

REPORT

2021-042

口防回

Prtis

$7 \mathrm{xy}$

回然皮
The mission of Wageningen University \& Research is "To explore the potential of nature to improve the quality of life". Under the banner Wageningen University \& Research, Wageningen University and the specialised research institutes of the Wageningen Research Foundation have joined forces in contributing to finding solutions to important questions in the

domain of healthy food and living environment. With its roughly 30 branches, 6,500 employees (5,500 fte) and

12,500 students, Wageningen University \& Research is one of the leading organisations in its domain. The unique

Wageningen approach lies in its integrated approach to issues and the collaboration between different disciplines. 